\title{
ЭКОНОМИЧЕСКАЯ ЭФФЕКТИВНОСТЬ АРЕНДЫ НЕДВИЖИМОГО ИМУЩЕСТВА ДЛЯ АРЕНДАТОРА С УЧЕТОМ КАДАСТРОВЫХ СВЕДЕНИЙ
}

\section{Яна Сергеевна Скрылева}

Сибирский государственный университет геосистем и технологий, Россия, 630108, г. Новосибирск, ул. Плахотного, 10, обучающийся, e-mail: yana.tishhenko.95@mail.ru

\section{Анастасия Леонидовна Ильиных}

Сибирский государственный университет геосистем и технологий, Россия, 630108, г. Новосибирск, ул. Плахотного, 10, кандидат технических наук, доцент кафедры кадастра и территориального планирования, тел. (383)344-31-73, e-mail: ilinykh_al@mail.ru

Особенностью сделки аренды недвижимого имущества является то, что объекты недвижимости передаются другой стороне в пользование, но не в собственность. Как утверждал великий философ Аристотель: «Богатство состоит в пользовании, а не в праве собственности». И эта мысль не потеряла смысла и значения и по сей день. Каждый предприниматель, анализируя валовую прибыль своего предприятия, принимает решение о том, эффективна ли для его организации аренда помещения экономически. Право сдачи объектов недвижимости в аренду принадлежит собственникам, то есть лицам, установленным законом как арендодатель. Такое лицо обязуется предоставить арендатору объект недвижимости за арендную плату во временное владение и пользование или только во временное пользование, согласно заключенному между ними договору аренды. Основным двигателем для функционирования рыночной экономики является принцип товарно-денежного обмена, в данном случае экономическую сущность аренды следует понимать, как товар в виде услуги передающийся в пользование на возмездной основе. Экономическим содержанием арендных отношений будет являться часть общей совокупности рыночных операций. Наиболее очевидной является экономическая форма аренды - величина арендной платы.

Ключевые слова: кадастровые сведения, экономическая выгодность аренды, недвижимое имущество, ставка арендной платы, арендатор, арендодатель

\section{ECONOMIC EFFICIENCY OF RENTING REAL ESTATE FOR THE TENANT TAKING INTO ACCOUNT CADASTRE INFORMATION}

\section{Yana S. Skryleva}

Siberian State University of Geosystems and Technologies, 10, Plakhotnogo St., Novosibirsk, 630108, Russia, Student, e-mail: yana.tishhenko.95@mail.ru

\section{Anastasia L. Ilyinykh}

Siberian State University of Geosystems and Technologies, 10, Plakhotnogo St., Novosibirsk, 630108, Russia, Ph. D., Associate Professor, Department of Cadastre and Territorial Planning, phone: (383)344-31-73, e-mail: linykh_al@mail.ru

A special feature of the real estate lease transaction is that the real estate objects are transferred to the other party for use, but not for ownership. As the great philosopher Aristotle claimed: "Wealth consists in use, not in ownership." And this thought has not lost its meaning and significance to this day. Each entrepreneur, analyzing the gross profit of his enterprise, decides whether the rent of premises is economically effective for his organization. The right to lease real estate belongs to the owners, that is, to persons established by law as a landlord. Such a person undertakes to provide the tenant with a real estate object for rent for temporary possession and use or only for temporary use, according 
to the lease agreement concluded between them. The main engine for the functioning of the market economy is the principle of commodity-money exchange, in this case, the economic essence of the lease should be understood as a product in the form of a service transferred to use on a paid basis. The economic content of the lease relationship will be part of the total set of market operations. The most obvious is the economic form of rent - the amount of rent.

Keywords: cadastral information, economic profitability of rent, real estate, rental rate, tenant, landlord

Одним из основных видов сделок с недвижимостью является ее аренда. В любом бизнесе на этапе его начала встает вопрос, что будет экономически выгоднее: аренда помещения для ведения бизнеса или же покупка такого помещения. В таком случае анализируется предполагаемая валовая прибыль предприятия, его расходы и принимается решение. Экономическая выгодность аренды как для арендодателя, так и для арендатора во многом зависит от размера арендной платы. Порядок, условия и сроки внесения арендной платы определяются договором аренды. Важнейшим условием деятельности на рынке недвижимости является полное и своевременное исполнение договорных обязательств. Структура стандартного договора аренды недвижимого имущества представлена на рис. 1[1].

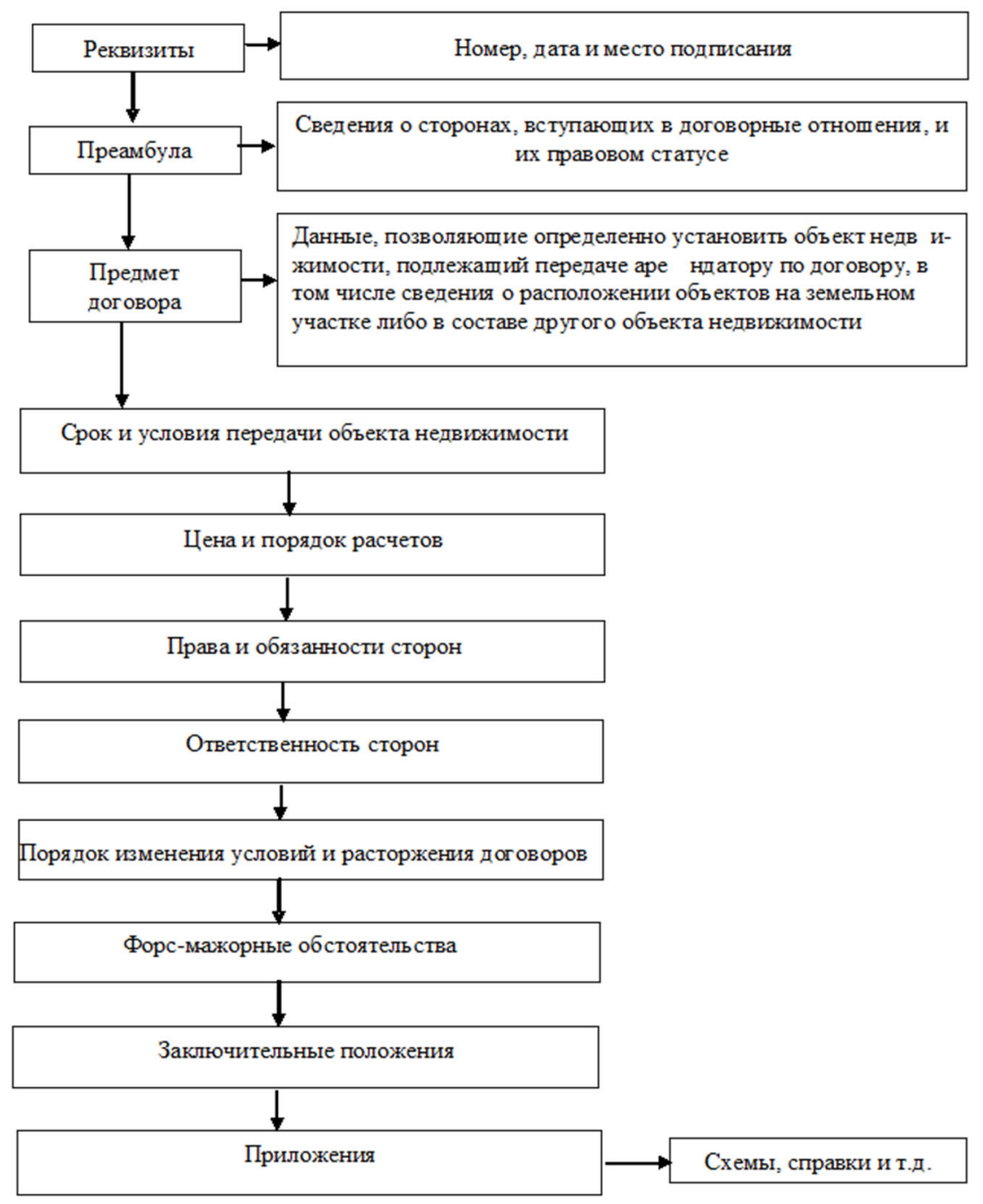

Рис. 1. Структура договора аренды 
В предмете договора должны быть указаны официальные характеристики объекта недвижимости, полученные из сведений Единого государственного реестра недвижимости (кадастровые сведения), такие как площадь, кадастровый номер и другие $[2,3]$.

Размер арендной платы также определяется договором аренды недвижимого имущества.

Арендная плата устанавливается за все арендуемое имущество в целом или отдельно по каждой его составной части. Рассмотрим экономическую выгодность аренды недвижимого имущества на примере среднестатистического новосибирского предприятия. Согласно статистике, средняя сумма арендной платы предприятия составляет 330000 рублей, за все арендуемое имущество. Наглядно такую статистику можно увидеть на рис. 2.

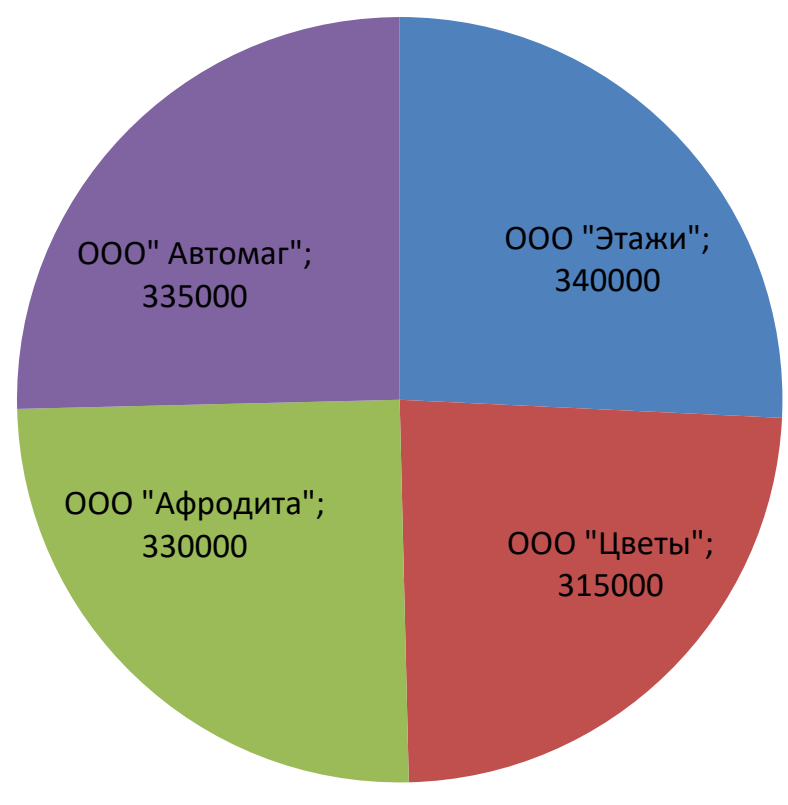

Рис. 2. Стоимость аренды помещений в г. Новосибирске

Согласно договору, размер арендной платы может изменяться по соглашению сторон в сроки, определенные договором, но не чаще одного раза в год. В предусмотренных законом случаях стороны могут использовать фиксированные ставки арендной платы, устанавливаемые государственными органами. А также могут устанавливать самостоятельно, исходя из своих расходов на помещение, а также исходя из экономической выгоды такого помещения [4].

В договоре аренды указывается не только годовая или ежемесячная арендная плата, но и периодичность внесения арендных платежей.

Если арендатор существенно и систематически нарушает сроки арендной платы, то арендодатель имеет право требовать досрочно: 
- внесения арендной платы, но не более чем за два срока подряд;

- расторжения договора, если арендатор не вносит арендную плату более двух сроков подряд [5].

Сумма арендной платы за помещение рассчитывается умножением ставки арендной платы на площадь здания:

$$
S_{a p}=a_{a p} \times U
$$

где $\mathrm{a}_{\mathrm{ap}}$ - ставка арендной платы за $1 \mathrm{~m}^{2}$ арендуемой площади;

$\mathrm{U}$ - общая площадь арендуемого здания или помещения [6].

Рассчитаем сумму арендной платы для среднестатистического помещения: $\mathrm{a}_{\mathrm{ap}}=2620$ рублей за $1 \mathrm{~m}^{2}, \mathrm{U}=126 \mathrm{~m}^{2}, \mathrm{~S}_{\mathrm{ap}}=2620 * 126=330000$ рублей.

Ставка арендной платы напрямую зависит от рыночной категории. Она зависит от арендных сделок в данном регионе (городе), т.е. от соотношения спроса и предложения на аренду данного вида имущества.

Кроме отмеченных рыночных факторов, ставка арендной платы на здания зависит от сопутствующих факторов, показанных на рис. 3.

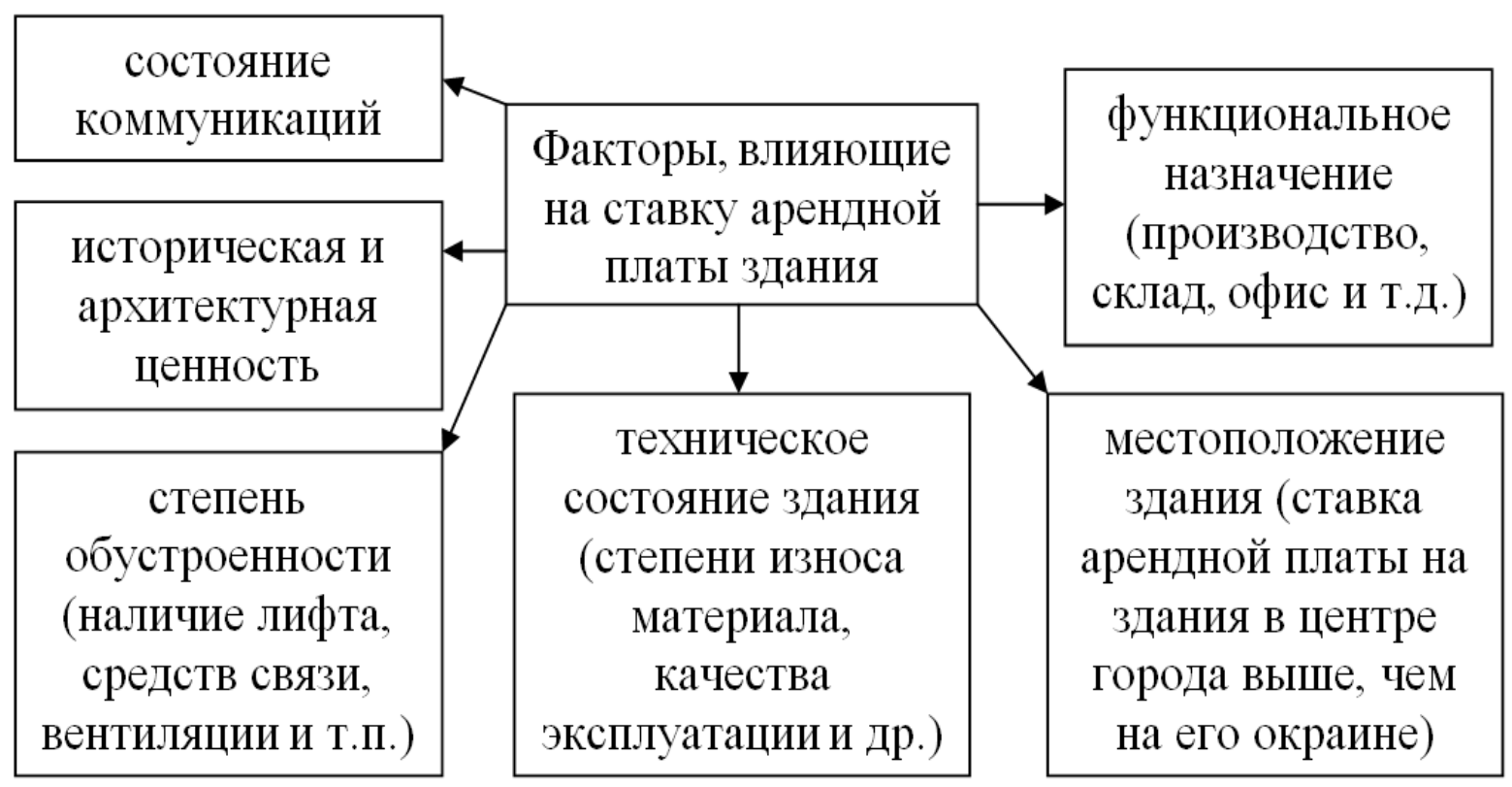

Рис. 3. Состав факторов, влияющих на ставку арендной платы здания [7]

Структура арендной платы зависит от того, как распределяются расходы по текущему ремонту арендуемого здания или помещения между арендодателем и арендатором. 
Все текущие платежи по содержанию здания (отопление, освещение, уборка мусора, охрана, мелкий ремонт и т.п.) несет арендатор, поэтому эти расходы нс включаются в арендную плату.

На арендатора ложится риск ответственности за сохранность арендуемого имущества, поэтому он оплачивает страховые взносы по имущественному страхованию, компенсируя эти расходы через арендные платежи [8].

Главный элемент в арендной плате, который определяет выгодность арендной сделки для арендодателя, - арендный процент. По экономическому смыслу арендный процент подобен банковскому проценту, он характеризует доход на вложенный капитал, передаваемый арендатору в виде имущества в натуральновещественной форме.

Арендатор рассчитывает выгодность аренды помещения исходя из планируемого чистого дохода, который он может получить от бизнеса, развернутого в арендуемом помещении.

Для этого арендатор составляет бюджет (смету) доходов и расходов на первый год аренды. При этом ему надо оценить:

- валовой доход (выручку от продаж или оборот);

- сумму операционных затрат на производство и реализацию продукции (услуг), включая затраты на материалы и услуги; расходы на содержание и текущий ремонт арендуемого помещения; заработную плату персонала с отчислениями (единый социальный налог); косвенные (накладные) расходы;

- плановую сумму прибыли [9].

Сумма арендной платы рассчитывается методом остатка, т.е. как остаток от валового дохода за вычетом всех операционных затрат и прибыли. Следовательно, сумма арендной платы в год:

$$
S_{a p}=B-3_{\text {оп }}-\Pi
$$

где В - валовой доход (выручка);

$3_{\text {оп }}$ - текущие операционные затраты;

П - планируемая сумма прибыли.

Данные для расчета: $\mathrm{B}=2000000$ руб., $3_{\text {оп }}=1100000$ руб., П=500000 руб.

$\mathrm{S}_{\mathrm{ap}}=2000000-1100000-500000=400000$ руб.

Остаток составляет 400000 рублей, сумма арендной платы 330000 рублей. Следовательно, аренда является выгодной для организации.

Достоинства и недостатки аренды недвижимости для арендатора показаны на рис. 4.

Примеряясь к арендной сделке, в данном случает, взвесив все обстоятельства, свидетельствующие как «за», так и «против» заключения договора аренды, можно принять решение заключить договор аренды. 


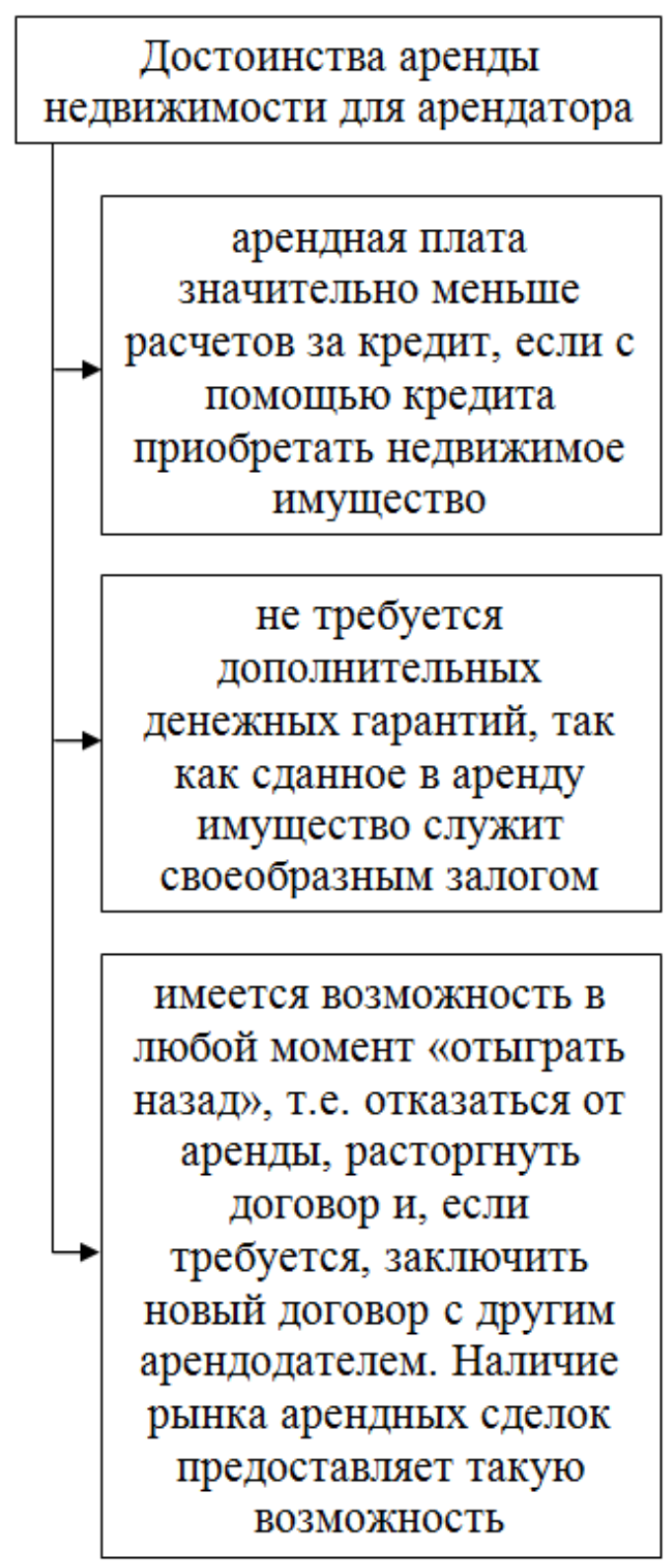

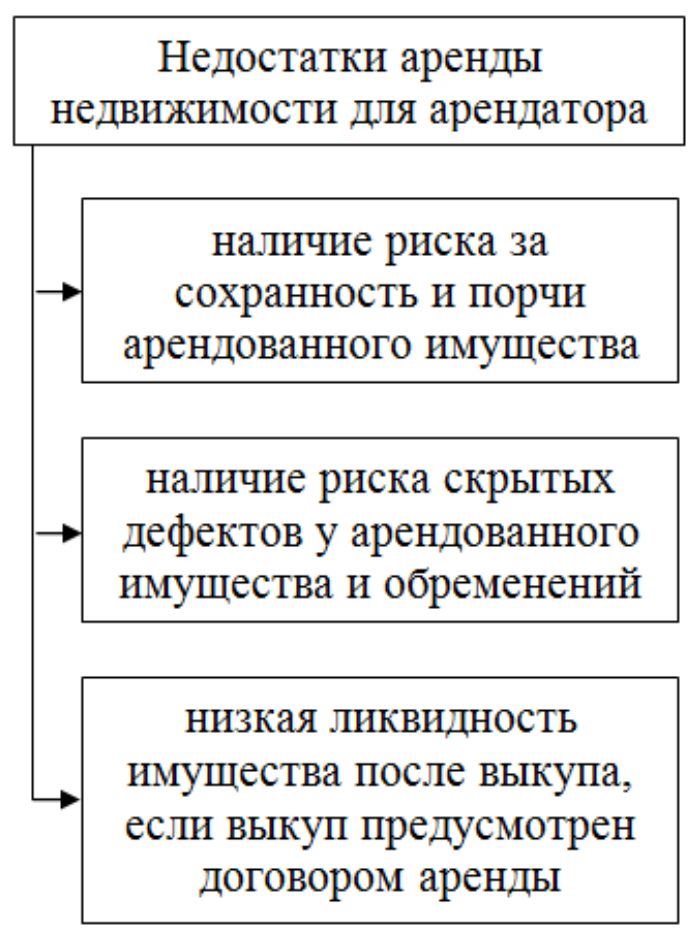

Рис. 4. Достоинства и недостатки аренды недвижимости для арендатора [10]

\section{БИБЛИОГРАФИЧЕСКИЙ СПИСОК}

1. Тысяча и один договор / ред. Г.Ю. Касьянова. - М.: Информ центр 21 века; Издание 5-е, перераб. и доп., 2015. - С. 16.

2. Анализ ценообразующих факторов, оказывающих влияние на кадастровую стоимость недвижимости / А. В. Дубровский, А. Л. Ильиных, О. И. Малыгина, В. Н. Москвин, А. В. Вишнякова // Вестник СГУГиТ. - 2019. - Т. 24, № 2. - С. 150-169.

3. Клюшниченко В. Н., Ивчатова Н. С. Особенности формирования кадастра в России// Вестник СГУГиТ. - 2020. -Т. 25, № 2 - С. 198-208.

4. Аренда и купля-продажа недвижимости. Комментарии и образцы документов / ред. ТихомироваМ.Ю. Под.. - М.: Издание Тихомирова М. Ю., 2013. - С. 156-158.

5. Аренда имущества. Судебная практика и образцы документов. - М.: Издание Тихомирова М. Ю., 2012. - С. 18. 
6. Тихомиров, М. Ю. Договоры в коммерческой деятельности / М. Ю. Тихомиров, О. М. Оглоблина. - Москва: СПб. [и др.] : Питер, 2012. С. 12-16.

7. Чижова А.С. Договор аренды нежилого помещения: что должны знать арендатор и арендодатель // Главбух. - №3. - февраль 2001 г. С.15-17.

8. Комарова Т.Ю. Нежилые помещения как объект аренды // Законодательство. - 2016. №12. C. 18.

9. Голомазова Л.А. Аренда нежилых помещений: законодательство и судебная практика // Бухгалтерский учет. - №15. - 2015. С. 16.

10. Исрафилов И. Аренда нежилых помещений // Хозяйство и право. - 2018. - №10. С. 28.

(C) Я. С. Скрылева, А. Л. Ильиных, 2021 